\title{
Sınıf Öğretmeni Görüşlerine Göre Sınıf İçi Öğrenci Davranışlarını Belirleme Ölçeği Geçerlilik ve Güvenirlik Çalışması
}

DOI: $10.26466 /$ opus. 827286

*

\author{
Celalettin Celebi* - Süleyman Arslantaş ** \\ * Doktor Öğretim Üyesi, Necmettin Erbakan Üniversitesi, Ereğli Eğitim Fakültesi, Konya/Türkiye \\ E-Posta: celalcelebi75@gmail.com \\ ORCID: 0000-0002-2189-6403 \\ *Doktor Öğretim Üyesi, Necmettin Erbakan Üniversitesi, Ahmet Keleşoğlu Eğitim Fakültesi, \\ Konya/Türkiye \\ E-Posta: suleymanarslantas@gmail.com \\ ORCID: $\underline{0000-0002-4989-2893}$
}

\begin{abstract}
Öz
Bu çalışma ile sını öğretmeni görüşlerine göre öğrencilerin sınıf içindeki olumlu ve olumsuz davranışlarının belirlenmesi için "Sınıf Öğretmeni Görüşlerine Göre Sını İçi Öğrenci Davranışlarını Belirleme Ölçeği'nin" geliştirilmesi amaçlanmıştır. Araştırma kapsamında öğrencilerin sınıf içi davranışlarını belirlemek için 44 maddeden oluşan beşli likert tipi anket formu hazırlanmıştır. Araştırma genel tarama modeline uygun desenlenmiştir. Araştırmanın evrenini 2019-2020 eğitim-öğretim yılında Konya'daki devlet okullarında görev yapan sını öğretmenleri oluşturmuştur. Araştırmanın örneklemini evrenden seçkisizlik yoluyla belirlenen gönüllü öğretmenler oluşturmuştur. Araştırma kapsamında 232 anket değerlendirmeye alınmış, edilen veriler istatistik programı ile analiz edilmiştir. Ölçeğin güvenirlik analizinde Cronbach alfa değeri 0,94 olarak bulunmuş, buna göre güvenirliğin yüksek olduğu belirlenmiştir. Kaiser-Meyer Olkin $(K M O=0,93)$ ve Bartlett Küresellik Testi $(\chi 2=3258,89)$ ile verilerin analiz için uygunluğu belirlenmiştir. Yapılan açımlayıcı faktör analizi ile ölçeğin "Olumlu Davranışlar" ve "İstenmeyen Davranışlar" olarak iki faktör ve 23 maddeden oluştuğu belirlenmiştir. Ölçeğin alt boyutlarının güvenirlik katsayılarının "Olumlu Davranışlar" için 0.84, "İstenmeyen Davranışlar" için ise 0,93'tür.
\end{abstract}

Anahtar Kelimeler: İstenmeyen öğrenci davranışları, olumlu davranışlar, ölçek geliştirme 


\title{
Validity and Reliability Study of the Scale for Determining In-Class Student Behaviors in Terms of Primary Teachers' Wiews
}

\begin{abstract}
With this study, it was aimed to develop the "Scale of Determining In-Class Student Behaviors According to Classroom Teacher's Views" in order to determine the positive and negative behaviors of the students in the classroom according to the opinions of the primary teacher. Within the scope of the research, a five-point likert type questionnaire consisting of 44 items was prepared to determine the inclass behaviors of the students. The research was designed in accordance with the general survey model. The universe of the study was formed by the classroom teachers working in state schools in Konya in the 2019-2020 academic year. The sample of the study consisted of volunteer teachers who were selected from the universe through randomness. Within the scope of the research, 232 questionnaires were evaluated and the data obtained were analyzed with a statistical program. In the reliability analysis of the scale, the Cronbach alpha value was calculated as 0.94 , and accordingly, the reliability was determined to be high. The suitability of the data for analysis was determined by using Kaiser-Meyer Olkin (KMO $=0.93)$ and Bartlett's Test of Sphericity $(\chi 2=3258.89)$. With the exploratory factor analysis, it was determined that the scale consists of two factors and 23 items as "Positive Behaviors" and "Unwanted Behaviors". The reliability coefficients of the sub-dimensions of the scale were found 0.84 for "Positive Behaviors" and 0.93 for "Unwanted Behaviors".
\end{abstract}

Keywords: Unwanted student behavior, positive behavior, scale development. 


\section{Giriş}

Eğitim ortamında özellikle de sınıf içinde, öğretmen ve öğrenciler çevrenin etkilerinden kısmen bağımsız olarak programın hedeflerini gerçekleştirmek için bulunurlar. Sınıf içinde yapılan öğrenme-öğretme etkinliklerinin amacına ulaşabilmesi için öğretmenin sınıfı etkili biçimde yönetme becerisine sahip olmalıdır. Öğretmenin sınıf yönetmesi hem eğitsel hem de yasal zorunluluk içerir. Ancak bu öğretmenin kendi dışındaki bütün değişkenleri de göz önünde bulundurmalıdır. Öğretmenin tutumu sınıf iklimini olumlu veya olumsuz biçimde etkiler (Ada ve Baysal, 2020). Bu yüzden öğretmenin, sınıf kurallarını öğrencilerle birlikte oluşturma, istenmeyen davranışları azaltma, zamanı etkili kullanma, öğrencileri sınıf içi etkinliklere katılmaya motive etme, derse karşı olumlu tutum geliştirme ve etkili öğrenme için olumlu iklim oluşturma gibi hususlarda bilgi ve beceri sahibi olması gerekmektedir.

Eğitim-öğretim etkinliğinin üretim yeri olan sınıfların fiziksel yapısı ile öğrencinin özellikleri, öğretmenin yeterliliği sınıf yöntemi için büyük önem taşımaktadır. Sınıfta yönetici konumundaki kişi öğretmendir (Celep, 2008). S1nıf yönetimi, sınıf ortamından, bireyin psikolojik özelliklerinden ve sınıf dışı etkenlerden etkilenir. Bu yüzden sınıf yönetimi bazı zorlukları içerir. Etkili sınıf yönetimi eğitimi almış ve öğrendiklerini uygulayabilen öğretmenler bu zorlukları önceden tahmin ederek gerekli önlemleri alabilirler. Bu zorlukları aşmak, sınıf yönetimini etkileyen faktörleri bilmeyi ve sorun çözmede yaratıcı olmayı gerektirir (Taş, 2008). Öğretmen ve öğrenci arasındaki ilişki sınıfın en önemli ögesini oluşturmaktadır (Balay, 2014). Öğrenci ve öğretmen arasındaki ilişkiyi olumlu biçimde oluşturmak ve sürdürmek sınıf iklimine olumlu katkı yapacaktır. Ancak öğrenme ve öğretme sürecini olumsuz etkileyen, engelleyen, sınıf düzenini bozan istenmeyen davranışlar da meydana gelmektedir.

İstenmeyen (olumsuz) öğrenci davranışları, sınıfta eğitsel hedeflerin gerçekleştirilmesini engelleyen ve öğretmen ve öğrencileri de olumsuz biçimde etkileyen davranışlardır (Akçadağ, 2007; Başar, 2011). Bunların olumsuz etkileri farklı derece ve boyutlarda olabilir. Bu açıdan istenmeyen davranışlar, "yıkıcı olandan", "çok yıkıcı olana" doğru uzanan bir yelpazede sıralanır (Başar, 2011). Onay gören davranışlar, istendik; reddedilen davranışlar ise, istenmeyen davranışlar olarak adlandırılır (Okutan, 2006). Öğrenmeyi bozan dav- 
ranışlar olarak da tanımlanan istenmeyen davranışlar, her tür sınıf seviyesinde eğitim ortamını olumsuz biçimde etkilemektedir (Johnson, Claus, Goldman ve Sollitto, 2016). Buna göre öğrenme öğretme sürecinin etkisini azaltan, sınıfın düzenini olumsuz etkileyen her tür davranış istenmeyen davranış kabul edilmektedir. Charles ve Senter (2005)'e göre öğrencilerin sınıf içi olumsuz davranışlarının diğer öğrencilerin öğrenme hakkını engelleme, öğretmenlerin öğretme görevlerini aksatma, zaman israfı etme, öğrencilerin motivasyonunu ve enerjisini azaltma, sınıf ortamında öğrenciler ve öğretmenler için korku ve stres yaratma, güveni zedeleme ve öğretmenler öğrenciler arasındaki işbirliğini zayıflatma gibi sonuçları olmaktadır.

Sınıf içinde meydana gelen istenmeyen davranışlarının nedenlerinin farklı ve karmaşık olmakla birlikte sosyal ve psikolojik pek çok nedeni olabilir (Aksoy, 2000). Öğrencilerin sınıf içindeki istenmeyen davranışlarını farklı unsurlar etkileyebilir. Tertemiz (2000), istenmeyen öğrenci davranışlarının nedenlerini; öğrenci kaynaklı, aile kaynaklı ve öğretmen kaynaklı olmak üzere üç gruba ayırmaktadır. Bu üç gruptaki nedenler sınıf içi davranışları da etkilemektedir.

Öğretmenler sınıf içi olumsuz davranışları engellemek ve etkili öğrenme ortamlar oluşturabilmek için farklı yöntemler kullanmaktadırlar. Daha önce yapılan çalışmalarda öğretmenlerin sınıfı içi olumsuz davranışları engellemek için uyarma, davranışın nedenini araştırma, aile ile iletişim kurma, davranışın yanlış olduğunu anlatma, kuralları hatırlatma, ceza ve eğlendirici öğretim, olumlu davranış gösteren öğrenciyi örnek göstermek, öğrenciyi derse dahil etmek, öğrenciyi onore eden sözlerle derse devam etmek, öğrenciye hafifçe dokunmak, öğrenciye fiziksel şiddet uygulamak, öğrencinin yerini değiştirmek, dikkat çekici materyal kullanmak gibi yöntemleri kullandıkları belirlenmiştir (Aksoy, 1999; Çelebi, 2019; Erdem, 2016; Kılıçoğlu, 2015; Türnüklü ve Galton, 2001; Uğurlu, Doğan, Şoförtakımcı, Ay ve Zorlu, 2014). Sınıf içinde olumsuz davranışları gidermek için en etkili strateji ise sınıf içinde uygulanabilir net kuralları belirlemektir (Kyriacou, 2010).

Farklı araştırmacılar tarafından farklı sınıf düzeylerinde yapılan çalışmalarla öğrencilerin sınıf içi olumsuz davranışlarını belirlenmesi hedeflenmiştir (Demir, 2011; Erdem, 2016; Kılıçoğlu, 2015; Türnüklü ve Galton, 2001; Uğurlu, Doğan, Şoförtakımcı, Ay ve Zorlu, 2014). Bu amaçla Balcı, Çapri, Çelikkaleli ve Büte (2006) tarafından geliştirilmiş Sınıf İçi İstenmeyen Öğrenci Davranışları Ölçeği bunlardan biri olup, bu ölçek ile öğrencilerin sınıf içi 
olumsuz davranışlarının neler olduğunun belirlenmesi hedeflenmiştir. Üstün ve Demir (2015) tarafından fen ve teknoloji öğretmenlerinin laboratuvar ortamlarında karşılaştıkları istenmeyen öğrenci davranışlarını belirlemek amacıyla 102 maddelik bir ölçek geliştirilmiştir. Tanhan ve Şentürk (2011)'ün çalışmasında ise Sınıf İçi İstenmeyen Öğrenci Davranışlarına Yönelik Öğretmen Tutumları Ölçeği ile ilköğretim düzeyindeki öğrencilerin sınıf içi olumsuz davranışlarına ilişkin öğretmen tutumları belirlenmeye çalışılmıştır.

Alan yazın incelendiğinde, sadece ilkokul kademesinde kullanılabilecek öğretmen görüşlerine göre öğrencilerin sınıf içi olumlu ve olumsuz davranışlarını belirlemeye yönelik bir ölçme aracının olmadığı görülmüştür. Bu nedenle ilkokuldaki öğrencilerin sınıf içi olumlu ve olumsuz davranışlarının öğretmen görüşlerine göre belirlenmesine yönelik 5'li likert biçiminde bir ölçme aracının geliştirilmesi amaçlanmaktadır. Sınıf içinde öğrencilerin olumlu davranışların pekiştirilmesi, olumsuz davranışlarının belirlenmesi ve bunun istendik biçimde değiştirilmesi; sınıf iklimini olumlu biçimde etkileyerek öğrenme ve öğretme sürecinin daha etkili bir şekilde düzenlenmesine ve sürdürülmesine fırsat verecektir. Ayrıca olumlu davranışların da belirlenerek pekiştirilmesi de istendik davranışların kalıcı hale gelmesine imkân sağlayacaktır. Sınıf içinde öğrencilerin istenmeyen ve olumlu davranışlarının neler olduğunun öğretmen tarafından bilinmesi öğretmenin sınıf yönetimine olumlu yönde katkı sunacaktır.

\section{Yöntem}

Öğretmen görüşlerine göre öğrencilerin sınıf içindeki davranışlarının belirlenmesinin amaçlandığı bu çalışma tarama modelli bir çalışmadır. Tarama çalışmaları, bir konuyla ilgili olarak katılımcıların görüş, tutum vb. niteliklerin belirlendiği ve diğer araştırma yöntemlerine göre daha büyük örneklemlere ulaşabilmeyi sağlar (Büyüköztürk, Çakmak, Akgün, Karadeniz ve Demirel, 2008).

\section{Çalışma Grubu}

Ölçek geliştirmenin hedeflendiği bu araştırmanın evrenini 2019-2020 eğitimöğretim yılında devlet okullarında görev yapan sınıf öğretmenleri oluşturmaktadır. Araştırmanın örneklemi ise Konya merkez ilçelerinde görev yapan ve çalışma evreninden seçkisiz örneklem belirleme yöntemiyle seçilen ve gö- 
nüllü olarak katılmayı kabul eden öğretmenlerden oluşmaktadır. Araştırmaya 120 kadın öğretmen ve 112 erkek öğretmen olmak üzere 232 sınıf öğretmeni katılmıştır. Çalışma grubuna ait bilgiler Tablo 1'de verilmiştir.

Tablo 1. Katılımcı bilgileri

\begin{tabular}{|c|c|c|c|}
\hline Değişken & & $\mathbf{N}$ & Toplam \\
\hline \multirow{2}{*}{ Cinsiyet } & Kadın & 120 & \multirow{2}{*}{232} \\
\hline & Erkek & 112 & \\
\hline \multirow{4}{*}{ Sınıf Düzeyi } & 1. Sinif & 55 & \multirow{4}{*}{232} \\
\hline & 2. Sinif & 62 & \\
\hline & 3. Sinif & 56 & \\
\hline & 4. Sinif & 59 & \\
\hline \multirow{6}{*}{ Kıdem } & $1-5 \mathrm{yll}$ & 27 & \multirow{6}{*}{232} \\
\hline & $6-10 \mathrm{yll}$ & 43 & \\
\hline & $11-15 \mathrm{yll}$ & 48 & \\
\hline & $16-20 \mathrm{yll}$ & 45 & \\
\hline & $21-25 \mathrm{yll}$ & 44 & \\
\hline & 26 yll ve üstü & 25 & \\
\hline
\end{tabular}

\section{Veri Toplama Aracı Geliştirme Süreci ve Verilerin Analizi}

Öğrencilerin sınıf içi davranışlarını belirlemek için yapılan bu çalışmada; alan yazından, uzman, öğretmen ve öğrencilerin görüsslerinden yararlanılarak ihtiyaç analizi adımlarına uygun şekilde elde edilen verilerle 44 maddelik taslak ölçek oluşturulmuştur. Daha sonra 50 sinıf öğretmenden oluşan gruba pilot uygulama yapılmış ve biçim, yazım, anlatım açısından gerekli düzeltmeler yapıldıktan sonra deneme uygulamasına geçilmiştir. Taslak ölçek, kişisel bilgiler ve öğrenci davranışları olmak üzere iki bölümden oluşmaktadır. Taslak ölçekteki maddeler 0'dan 4'e doğru 0-Hiçbir Zaman, 1-Nadiren, 2-Bazen, 3-Sık sık, 4-Her Zaman olmak üzere 5'li likert yapıdadır.

Hazırlanan taslak, Konya'daki devlet okullarında görev yapan öğretmenlere uygulanmıştır. Toplam 300 adet çoğaltılan formlardan 250'si öğretmenler tarafından doldurulmuş, bunlardan 18'i hatalı veya eksik olduğu için ç1kartılmış, toplam 232 form analiz sürecine dahil edilmiştir.

Ölçek taslağının güvenirlik çalışması için; ölçekten elde edilen puanların iç tutarlılı̆̆ını belirlemeye yönelik Cronbach Alfa güvenirlik katsayısı, her maddenin alt-üst \%27 gruplarının madde ortalama puanları arasındaki ilişkisiz $t$ testi, testin iki yarı güvenirliği, elde edilen değerin tüm testin güvenirlik değeri haline gelmesi adımı olan Spearman-Brown korelasyon değeri ve 
her bir maddeye ait düzeltilmiş madde toplam korelasyonları hesaplanmıştır. Böylece madde-test uyumu, iki yarı güvenirliği gibi uygulamalarla iç tutarlık anlamında güvenirlik tespit edilmiş oldu. İç tutarlık anlamında güvenirlik aynı zamanda yapı geçerliğini belirlemenin de önkoşulu durumundadır (Bland ve Altman, 1997).

Cronbach Alpha katsayısı, ölçekte yer alan maddelerin varyansları toplamının genel varyansa oranlaması ile bulunan bir ağırlıklı standart değişim değeridir. Ölçekte Cronbach Alpha ne kadar yüksek olursa ölçekteki maddelerin birbiriyle tutarlı olduğu ve aynı özelliği yokladığı iddia edilebilir. Cronbach Alpha katsayısı istatistik temelleri tutarlı ve tüm maddeleri dikkate alarak hesaplandığından, genel güvenirlik yapısını diğer katsayılara göre en iyi yansitan katsayıdır (Bland ve Altman, 1997).

Uygulama sonucunda elde edilen verilerle ölçek taslağının faktör yapısının belirlenmesi amacıyla açımlayıcı faktör analizi yapılmıştır. Faktör analizi sonucunda ölçeğin iki faktörlü bir yapıya sahip olduğu belirlenmiştir. İki boyutlu yapının geçerliğinin test edilmesi için Açımlayıcı Faktör Analizi (AFA) yapılarak birbirine anlamca benzeyen ve faktör yükü $0,4^{\prime}$ ün altında kalan maddeler çıkarılmış ve 23 maddelik nihai form elde edilmiştir. Ölçekten alınabilecek en yüksek puan 92'dir. Verilerin analizinde güvenirlik ve geçerlik belirlemeye yönelik istatistiklere yer verilirken bu istatistiklerin hesaplanmasinda istatistik programlarından yararlanılmıştır.

\section{Bulgular}

Bu araştırmada Sınıf Öğretmeni Görüşlerine Göre Sınıf İçi Öğrenci Davranışlarını Belirleme Ölçeği'nin geçerlik ve güvenirlik çalışması iki bölümde verilmiştir.

\section{Sını Öğretmeni Görüşlerine Göre Sını İçi Öğrenci Davranışların Belirleme Ölçeği'nin Güvenirlik Çalışması}

Ölçeğin güvenirliği; Cronbach Alpha iç tutarlılık katsayısı, iki yarı test arası korelasyon değeri, Spearman Brown iki yarı test güvenirlik katsayısı uygulaması ile elde edilen puanlar arasındaki ilişkilere ait madde toplam puan korelasyon katsayısı hesaplanarak incelenmiştir. Elde edilen sonuçlar Tablo 2 ve Tablo 3'te yer almaktadır. 
İki yan test güvenirlik analizi: Ölçeğin güvenirliğini belirlemek için iç tutarlılığı belirleme yöntemlerinden olan biri olan iki yarı güvenirlik (split half) analizi yapılmıştır. Tablo 2`de Sınıf Öğretmeni Görüşlerine Göre Sınıf İçi Öğrenci Davranışlarını Belirleme Ölçeği'nin iki yarı güvenirlik analizi sonucunda elde edilen bulgulara yer verilmiştir.

Tablo 2. Sinı Öğretmeni Görüsslerine Göre Sinıf İçi Öğrenci Davranışlannı Belirleme Ölçeği'nin iki yan güvenirlik analizi

\begin{tabular}{llll}
\hline \multirow{4}{*}{ İki Yarı Cronbach Alpha Değerleri } & \multirow{2}{*}{ 1. Yarı } & Değer & $0,88^{*}$ \\
\cline { 2 - 4 } & \multirow{2}{*}{ Madde Sayısı } & 12 \\
\cline { 2 - 4 } & 2. Yarı & Değer & $0,93^{*}$ \\
\cline { 2 - 4 } & Toplam Madde Sayısı & Madde Sayısı & 11 \\
\hline Formlar Arası Korelasyon & & $0,71^{*}$ \\
\hline Spearman-Brown Güvenirlik & & 0,83 \\
\hline Birinci yarı: 1- 12. Maddeler & İkinci yarı: 13- 23. maddeler &
\end{tabular}

Tablo 2'de görüldüğü gibi birinci yarının 1, 2, 3, 4, 5, 6, 7, 8, 9, 10, 11 ve 12 . maddelerden oluştuğu ve Alpha değerinin 0,88 olduğu, ikinci yarımın ise 13, $14,15,16,17,18,19,20,21,22$ ve 23. maddelerden oluştuğu ve Alpha değerinin 0,93 olduğu görülmektedir. Spearman-Brown katsayısı 0,83'tür. Bulgulara göre ölçeğin iç tutarlılığı 0,70 değerinin üzerinde olduğu için güvenirliğin yüksek olduğu söylenebilir (Bland ve Altman, 1997).

Madde toplam puan korelasyon analizi: Bu bölümde ölçme aracının madde, test bütünlügünü belirleme, her bir maddenin testle uyumunu ortaya koymak amaciyla yapılan istatistiki işlemlere yer verilmiştir. Tablo 3'te çalışma kapsaminda madde toplam puan korelasyon analiziyle elde edilen bulgular yer almaktadır.

Tablo 3. Sinff Öğretmeni Görüşlerine Göre Sinıf İçi Öğrenci Davranışlarnn Belirleme Ölçeğinin Madde Toplam Puan Korelasyon Analizi ( $N=232)$

\begin{tabular}{llll}
\hline & \multicolumn{2}{l}{ Madde-Toplam Puan Korelasyonları } & Madde Çıkarıldığında Cronbach Alfa Katsayısı \\
\hline Madde No & $\mathbf{r}$ & $\mathbf{p}$ & \\
Madde 1 & 0,59 & $0.00^{*}$ & 0,94 \\
Madde 2 & 0,48 & $0.00^{*}$ & 0,94 \\
Madde 3 & 0,53 & $0.00^{*}$ & 0,94 \\
Madde 4 & 0,55 & $0.00^{*}$ & 0,94 \\
Madde 5 & 0,58 & $0.00^{*}$ & 0,94 \\
Madde 6 & 0,40 & $0.00^{*}$ & 0,94 \\
Madde 7 & 0,68 & $0.00^{*}$ & 0,94 \\
Madde 8 & 0,59 & $0.00^{*}$ & 0,94 \\
Madde 9 & 0,62 & $0.00^{*}$ & 0,94 \\
Madde 10 & 0,65 & $0.00^{*}$ & 0,94 \\
Madde 11 & 0,53 & $0.00^{*}$ & 0,94 \\
\hline
\end{tabular}




\begin{tabular}{llll}
\hline Madde12 & 0,66 & $0.00^{*}$ & 0,94 \\
Madde 13 & 0,73 & $0.00^{*}$ & 0,93 \\
Madde14 & 0,70 & $0.00^{*}$ & 0,93 \\
Madde15 & 0,61 & $0.00^{*}$ & 0,94 \\
Madde16 & 0,76 & $0.00^{*}$ & 0,93 \\
Madde 17 & 0,66 & $0.00^{*}$ & 0,94 \\
Madde 18 & 0,72 & $0.00^{*}$ & 0,93 \\
Madde 19 & 0,70 & $0.00^{*}$ & 0,93 \\
Madde 20 & 0,76 & $0.00^{*}$ & 0,93 \\
Madde 21 & 0,66 & $0.00^{*}$ & 0,94 \\
Madde 22 & 0,58 & $0.00^{*}$ & 0,94 \\
Madde 23 & 0,63 & $0.00^{*}$ & 0,94 \\
\hline
\end{tabular}

Tablo 3'te görüldüğü gibi iç tutarlılık analizinde madde toplam puan korelasyonlarının 0.40- 0,76 arasında değiştiği, Cronbach Alpha güvenirlik katsayılarının ise 0.93 ve 0.94 olduğu görülmektedir. Buna göre elde edilen sonuçların oldukça güvenilir olduğu söylenebilir (Bland ve Altman, 1997).

Tablo 4'te ölçme aracının alt boyutlarının madde toplam puan korelasyonları ve Cronbach Alpha düzeyleri koyma amacıyla yapılan istatistiki işlemlere yer verilmiştir.

Tablo 4. Sinnf Öğretmenleri Göriusslerine Göre Sinf İçi Öğrenci Davranışlarnı Belirleme Ölçeği'nin Madde Toplam Puan Korelasyonlarn ve Alt Boyutlarmın Cronbach Alpha Dïzeyleri ( $n=232)$

\begin{tabular}{|c|c|c|c|c|}
\hline \multirow[b]{2}{*}{ Ölçek Alt Boyutları } & \multicolumn{3}{|c|}{ Madde-Toplam Puan Korelasyonları } & \multirow{2}{*}{$\begin{array}{l}\text { Cronbach } \\
\text { Alfa Katsayıs }\end{array}$} \\
\hline & Madde No & $\mathbf{r}$ & $\mathrm{p}$ & \\
\hline \multirow{11}{*}{ Olumlu Davranışlar } & Madde 1 & ,64 & $0.00^{*}$ & \multirow{12}{*}{, 84} \\
\hline & Madde 2 &, 51 & $0.00^{*}$ & \\
\hline & Madde 3 & 60 & $0.00^{*}$ & \\
\hline & Madde 4 & 61 & $0.00^{*}$ & \\
\hline & Madde 5 & 64 & $0.00^{*}$ & \\
\hline & Madde 6 & ,36 & $0.00^{*}$ & \\
\hline & Madde 7 & ,71 & $0.00^{*}$ & \\
\hline & Madde 8 & 60 & $0.00^{*}$ & \\
\hline & Madde 9 &, 58 & $0.00^{*}$ & \\
\hline & Madde 10 &, 59 & $0.00^{*}$ & \\
\hline & Madde 11 & 48 & $0.00^{*}$ & \\
\hline \multirow{12}{*}{ İstenmeyen Davranışlar } & Madde 12 & 69 & $0.00^{*}$ & \\
\hline & Madde 13 & ,77 & $0.00^{*}$ & \multirow{11}{*}{,93 } \\
\hline & Madde 14 & ,72 & $0.00^{*}$ & \\
\hline & Madde 15 & 66 & $0.00^{*}$ & \\
\hline & Madde 16 &, 80 & $0.00^{*}$ & \\
\hline & Madde 17 & ,70 & $0.00^{*}$ & \\
\hline & Madde 18 & ,75 & $0.00^{*}$ & \\
\hline & Madde 19 & ,75 & $0.00^{*}$ & \\
\hline & Madde 20 & ,78 & $0.00^{*}$ & \\
\hline & Madde 21 & 68 & $0.00^{*}$ & \\
\hline & Madde 22 & 61 & $0.00^{*}$ & \\
\hline & Madde 23 & 60 & $0.00^{*}$ & \\
\hline
\end{tabular}


Ölçeğin her bir alt boyutunda yer alan maddelerin puanları ile yer aldığı alt boyutun toplam puanı arasındaki ilişki korelasyon analizi ile değerlendirilmiştir. Tablo 4'te görüldüğü gibi ölçeğin alt boyutlarının güvenirlik katsayılarının Cronbach Alfa değerleri "Olumlu Davranışlar” alt boyutu için 0.84, "İstenmeyen Davranışlar" alt boyutu için 0,93 olarak tespit edilmiştir. Bulgulara göre ölçeğin her iki alt boyutunda yer alan maddelerin puanları ile bulunduğu alt boyutun toplam puanı arasında pozitif yönde yüksek düzeyde anlamlı ilişki olduğu söylenebilir.

\section{Sını Öğretmeni Görüşlerine Göre Sını İçi Öğrenci Davranışların Belirleme Ölçeği'nin geçerlilik çalışması}

Sınıf Öğretmeni Görüşlerine Göre Sınıf İçi Öğrenci Davranışlarını Belirleme Ölçeği'nin Geçerlilik Çalışması için içerik/kapsam geçerliği ve faktör analizi yapılmıştır.

Kapsam geçerliliği: Ölçeğin kapsam geçerliliğine yönelik Kendall W Uyuşum testi yapılmıştır. Test sonucunda, pilot uygulama yapılan 50 uzmanın görüşleri arasında anlamlı fark olmadığı belirlenmiştir (Kendall $\mathrm{W}=0.121 ; \mathrm{p}=0.249$ ).

Açımlayıcı faktör analizi: Açımlayıcı faktör analizi için öncelikle verilerin faktör analizi için uygunluğunun belirlenmesi gerekir (Bland ve Altman, 1997). Bu nedenle Kaiser-Meyer Olkin (KMO) ve Bartlett küresellik testi yapılmıştır. Faktör analizi için uygulanan Kaiser-Meyer Olkin $(\mathrm{KMO}=0,93)$ sonucu ile Bartlett Küresellik Testi ( $\chi 2=3258,89 ; p<0,001$ ) sonucuna göre verilerin faktör analizi yapmak için uygun olduğu tespit edilmiştir (Bland ve Altman, 1997). Tablo 5'te Kaiser-Meyer Olkin (KMO) ve Bartlett Küresellik Testi sonuçları görülmektedir. 
Tablo 5. Kaiser-Meyer Olkin ve Bartlett Küresellik Testi Sonuçları

\begin{tabular}{lll}
\hline KMO (Kaiser-Meyer-Olkin Measure) & & 0,93 \\
& $\chi^{2}$ & 3258,89 \\
Bartlett Küresellik Testi & $\mathrm{Sd}$ & 253 \\
& $\mathrm{p}$ & 0,00 \\
\hline
\end{tabular}

Sınıf Öğretmeni Görüşlerine Göre Sınıf İçi Öğrenci Davranışlarını Belirleme Ölçeği'nin faktör desenini belirlemek için döndürülmemiş temel bileşenler analizi uygulanmıştır. 23 madde için yinelenen AFA sonuçları Tablo 6'da özetlenmiştir:

Tablo 6. Sını Öğretmeni Görüşlerine Göre Sinıf İ̧̧i Öğrenci Davranışların Belirleme Ölçeği'nin Faktör Analizi

\begin{tabular}{lcc}
\hline Ölçek Maddeleri & $\begin{array}{c}\text { Ölçeğin Alt Boyutları } \\
\text { Olumlu Davranışlar }\end{array}$ & İstenmeyen Davranışlar \\
\hline Madde 1 &, 63 & \\
Madde 2 &, 52 & \\
Madde 3 &, 56 & \\
Madde 4 &, 58 & \\
Madde 5 &, 62 & \\
Madde 6 &, 44 & \\
Madde 7 &, 72 & \\
Madde 8 &, 63 & \\
Madde 9 &, 65 & \\
Madde 10 &, 68 & \\
Madde 11 &, 57 &, 70 \\
Madde 12 & &, 77 \\
Madde 13 & &, 74 \\
Madde 14 & &, 66 \\
Madde 15 & &, 79 \\
Madde 16 &, 70 \\
Madde 17 & &, 76 \\
Madde 18 & &, 75 \\
Madde 19 & &, 80 \\
Madde 20 & &, 71 \\
Madde 21 & &, 62 \\
Madde 22 & & \\
Madde 23 & & \\
\hline
\end{tabular}

Faktör analizi sonucunda faktör yük değeri ve binişik durumlarına göre 21 madde ölçekten çıkarılmıştır. Bu maddeler ölçekten tek tek çıkarılmış ve faktör analizi birçok kez tekrar edilmiştir.

Açımlayıcı faktör analizi (AFA) sonucunda, maddelerin iki faktör altında toplandığı; birinci faktörde 11, ikinci faktörde ise 12 maddenin yer aldığı belirlenmiştir. Faktörlerdeki maddelerin ortak özelliklerine göre faktörler isim- 
lendirilmiştir. İstenen, sınıf ortamına olumlu katkı içeren maddelerin bulunduğu birinci faktöre "olumlu davranışlar", sınıf ortamını bozan eğitim ortamını olumsuz etkileyen maddelerin bulunduğu ikinci faktör ise "istenmeyen davranışlar" olarak isimlendirilmiştir. Faktörlerde yer alan maddelerin faktör yükleri birinci faktör için 0,44-0,72, ikinci faktör için 0,62-0,80 aralığındadır. Bu faktörlerin öz-değerleri ve açıkladıkları varyansın yüzdesi birinci faktör için 10,43 (\%45,36), ikinci faktör için 2,01 $(\% 8,75)$ olarak hesaplanmıştır. İki faktörün toplam varyansa katkısı yaklaşık \%54,11'dir. Açılayıcı faktörlerin toplam varyansa katkısı \%45-50 değerinden yüksek ise bu faktörlerin testi açıklama açısından yeterli kabul edilebilir (Bland ve Altman, 1997).

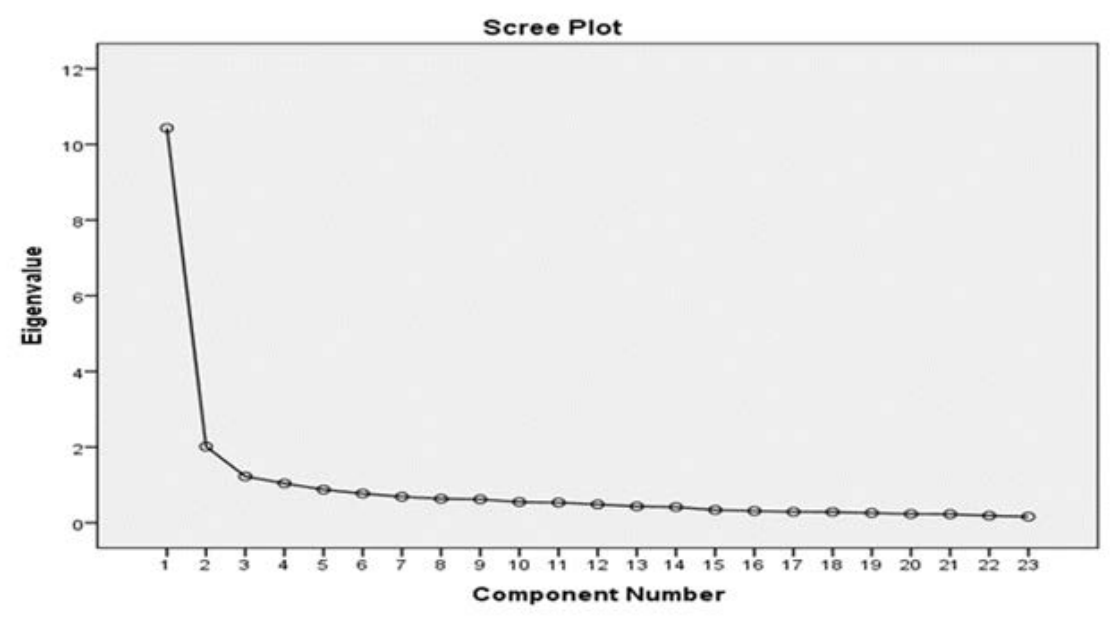

Şekil 1. Ölçeğin faktör yapısını gösteren yamaç-birikinti grafiği (scree plot)

Sonuç olarak elde edilen 23 madde ile faktör analizi yeniden yapılmıştır. Açımlayıcı faktör analiz sonucuna göre, Kaiser' in özdeğeri 1' den büyük olma kuralı ve Şekil 1'deki yamaç-birikinti grafiğinde de (scree plot) görüldüğü gibi ölçeğin iki faktörden oluştuğuna karar verilmiştir.

Ölçek geliştirme sürecinde Doğrulayıı Faktör Analizine gerek görülmemiştir. Ölçekle belirlenen verilerin kararlı özellikte olması, aynı amaçla yapılacak ikinci ölçümde aynı sonuçların elde edileceğine güven duyulması ve modelde olan alt boyutların tartışmaya veya şüpheye yer vermeyecek şekilde açık olması DFA kullanımını ve sonuçlarını etkisizleştirmektedir. Bu ölçek alanında belirlenen iki alt boyut; olumlu davranışlar ve istenmeyen davranışlardır. Bu iki alt boyut gerek, öğretim, gerek sınıf yönetimi, gerek psikoloji 
alanı tarafından bakıldığında ilk akla gelen boyutlar olarak öne çıkmakta ve belirsizlik taşımamaktadır. Doğrulayıcı faktör analizi, gizil değişkenler ile ilgili kuramların test edilmesinde ve daha üst seviyede kullanılan oldukça geniş bir tekniktir (Tabachnick ve Fidell, 2014). Bu çalışmada gizli değişken ortaya çıkarma veya onu test etme gibi bir amaç bulunmamaktadır.

\section{Tartışma ve Sonuç}

Açımlayıcı faktör analizi, aynı yapıyı ya da özelliği ölçen değişkenleri bir araya getirerek ölçmeyi daha az sayıda faktör ile açıklayan bir istatistiksel yöntemdir (Büyüköztürk, 2005). Açımlayıcı faktör analiziyle ölçekteki maddelerin iki faktör altında toplandığl; olumlu davranışlar faktör yükünün 0,440,72 ve istenmeyen davranışlar faktörünün ise $0,62-0,80$ aralığında değerler aldığ 1 belirlenmiştir. Faktör yük değerinin 0,71 olması mükemmel; 0,63 olması çok iyi; 0,55 olması; 0,45 olması orta ve 0,32 olması, zayıf düzeyde varyansa katkıda bulunduğunu göstermektedir. Dolayısıyla faktör analizi ile elde edilen sonuçların alan yazına uygun olduğu görülmektedir.

Ölçeğin güvenirliğini ölçmek için yapılan iki yarı güvenirlik (split half) analizinde birinci yarımın Cronbach Alpha değerinin 0,88 olduğu, ikinci yarımın Croanbach Alpha değerinin 0,93 olduğu belirlenmiştir. Ayrıca Spearman-Brown katsayısı da $(0,83)$ ölçeğin güvenilir olduğunu göstermektedir.

Ölçeğin, Cronbach alfa güvenirlik katsayısının 0.94 olduğu ve madde toplam puan korelasyonlarının ise 0.40- 0,76 arasında değiştiği belirlenmiştir. Buna göre elde edilen sonuçların oldukça güvenilir olduğu söylenebilir (Süt, 2009). Ölçeğin alt boyutlarının güvenirlik katsayılarının Cronbach Alfa değerlerinin "Olumlu Davranışlar" alt boyutu için 0.84 ve "İstenmeyen Davranışlar" alt boyutu için 0.93 olarak belirlenmesi; ölçeğin her iki alt boyutunda yer alan maddelerin puanları ile bulunduğu alt boyutun toplam puanı arasinda pozitif yönde yüksek düzeyde anlamlı ilişki olduğunu göstermektedir.

Araştırmacılar tarafından geliştirilen bu ölçme aracı, eğitim süreçlerinin başında verimli bir öğretim süreci planlayabilmek için eğitimcilere veri sağlayacaktır. Ayrıca ölçek ile sınıf yönetim süreçleri için uygun modelin seçimini kolaylaştırmak ve sınıf içi iletişimi sağlıklı hale getirmek için veriler elde edilebilir. Bu ve benzeri ölçme araçları gerek sınıf yönetiminde önlemsel, tepkisel veya demokratik modellerin uygunluğuna karar verirken, gerekse öğretimi modellerken kullanılacak verileri elde etmek için kullanılabilir. 


\title{
EXTENDED ABSTRACT
}

\section{Validity and Reliability Study of the Scale for Determining In-Class Student Behaviors in Terms of Primary Teachers' Wiews}

\author{
Celalettin Çelebi - Süleyman Arslantaş \\ Necmettin Erbakan University
}

Teacher's attitude affects the classroom climate in a positive or negative way (Ada and Baysal, 2020). Therefore, the teacher should have knowledge and skills in matters such as creating the classroom rules with students, reducing misbehaviors, using time effectively, motivating students to participate in classroom activities, developing a positive attitude towards the lesson and creating a positive climate for effective learning. The use of these knowledge and skills will help to provide a positive classroom atmosphere, as well as lack of use and interaction with other variables can create a negative classroom atmosphere and misbehavior. The reasons for misbehaviors in the classroom can be different and complex, but there may also be many social and psychological reasons for them (Aksoy, 2000). Students' misbehaviors in the classroom can be affected from many different factors.

Studies conducted by researchers at different class levels aimed to identify students' misbehaviors in the classroom (Demir, 2011; Erdem, 2016; Kılıçoğlu, 2015; Türnüklü and Galton, 2001; Uğurlu, Doğan, Şoförtakımcı, Ay and Zorlu, 2014). For this purpose, the In-Class Undesirable Student Behaviors Scale developed by Balcı, Çapri, Çelikkaleli, and Büte (2006) is one of them, and with this scale, it is aimed to determine the negative student behaviors in the classroom. A 102-item scale was developed by Üstün and Demir (2015) in order to determine undesirable behaviors faced by science and technology teachers in laboratory environments. In the study of Tanhan and Şentürk (2011), the teacher attitudes towards undesirable student behaviors in the classroom scale were used to determine the teachers' attitudes towards the undesirable behaviors of primary school students in the classroom. Through literature review it has come out that there are no measurement tools to de- 
termine the positive and negative behaviors of students in the classroom according to the teachers' opinions that can only be used at the primary school level. For this reason, it is aimed to develop a 5-point Likert-format measurement tool for determining the positive and negative behaviors of primary school students in the classroom according to teachers' opinions.

This study, which aims to determine the student behaviors in the classroom according to teachers' views, is a survey (Büyüköztürk, Çakmak, Akgün, Karadeniz, and Demirel, 2008). The universe of the study, in which scale development is aimed, consists of classroom teachers working in public schools in the 2019-2020 academic year. The sample of the study, on the other hand, consists of randomly selected teachers working in the central districts of Konya. A total of 232 classroom teachers, 120 females and 112 males, participated in the study.

In the study, a draft scale with 44 items has been created with the data obtained in accordance with the needs analysis steps by benefiting from the literature, experts, teachers and students' opinions. Next, a pilot application has been carried out to a group of 50 class teachers and the trial application has started after the necessary corrections have been made in terms of form, spelling and expression. The draft scale consists of two parts: personal information and student behavior. The items in the draft scale are in a 5-point likert structure from 0 to 4, 0-Never, 1-Rarely, 2-Sometimes, 3-Often, 4-Always. Out of the 300 forms, 250 were filled out by teachers, 18 of them were excluded because they were inaccurate or incomplete, and a total of 232 forms were analyzed.

For the reliability study of the draft scale; Cronbach's Alpha reliability coefficient scores obtained from the scale to determine the internal consistency, the unrelated $t$ test between the item average scores of $27 \%$ groups of each item, the two-half reliability of the test, the Spearman-Brown correlation value, which is the step where the obtained value becomes the reliability value of the whole test, and corrected total item correlations for each item have been calculated. Thus, reliability has been determined in terms of internal consistency with applications such as item-test fit and split half reliability. Reliability in terms of internal consistency is also a prerequisite for determining construct validity (Bland and Altman, 1997).

Using the data obtained, exploratory factor analysis has been carried out to determine the factor structure of the draft scale. As a result of the factor 
analysis, it has been found out that the scale has a two-factor structure. In order to test the validity of the two-dimensional structure, Explanatory Factor Analysis (EFA) has been carried out and items that are similar to each other and the ones having less than 0.4 factor loads have been removed, and the final form of the scale with 23 items have been obtained. The highest score that can be obtained from the scale is 92 .

Reliability of the Student Behavior Determination Scale: In order to determine the reliability of the scale, split half analysis, which is one of the methods of determining the internal consistency, has been done. The first half consists of items $1,2,3,4,5,6,7,8,9,10,11$ and 12 and the Alpha value is 0.88 , while the second half consists of 13, 14, 15, 16, 17, 18. , 19, 20, 21, 22 and 23rd items and its Alpha value is 0.93 . Spearman-Brown coefficient is 0.83 . In the internal consistency analysis, it has come out that item-total score correlations vary between 0.40 and 0.76, while Cronbach Alpha reliability coefficients are 0.93 and 0.94 . Accordingly, it can be said that the obtained results are quite reliable (Bland \& Altman, 1997). The relationship between the scores of the items in each sub-dimension of the scale and the total score of the sub-dimension have been determined by means of correlation analysis. Cronbach Alpha values are 0.84 for the "Positive Behaviors" sub-dimension and 0.93 for the "Unwanted Behaviors" sub-dimension. According to the findings, it can be concluded that there is highly significant positive correlation between the scores of the items in both sub-dimensions of the scale and the total score of the sub-dimension.

Validity study of the Student Behavior Determination Scale: The Kendall W Conformity test has been done for the content validity of the scale. As a result of the test, it has been found out that there are no significant differences between the opinions of 50 experts who have been piloted (Kendall $\mathrm{W}=0.121$; $\mathrm{p}=0.249$ ). For exploratory factor analysis, firstly, the suitability of the data for factor analysis must be determined (Bland and Altman, 1997). For this reason, Kaiser-Meyer Olkin (KMO) and Bartlett test of sphericity have been done. According to the result of Kaiser-Meyer Olkin $(\mathrm{KMO}=0.93)$ and Bartlett's Test of Sphericity $(\chi 2=3258.89 ; \mathrm{p}<0.001)$ the data have been found to be suitable for factor analysis (Bland \& Altman, 1997). As a result of the factor analysis, 21 items have been removed from the scale according to the factor load value and their overlapping status. These items have been removed from the scale one by one and factor analysis has been repeated many times. As a result 
of the exploratory factor analysis (EFA), it has been found that the items are grouped under two factors. It has come out that there are 11 items in the first factor and 12 items in the second factor. The factors are named according to the common properties of the items in the factors. The first factor that contains the desired items which contribute positively to the classroom environment is called "positive behaviors", and the second factor that contains items which disrupt the classroom environment negatively is called "unwanted behaviors". The factor loads of the items in the factors are between $0.44-0.72$ for the first factor and $0.62-0.80$ for the second factor. The eigenvalues of these factors and the percentage of variance they explain have been calculated as 10.43 $(45.36 \%)$ for the first factor and $2.01(8.75 \%)$ for the second factor. The contribution of the two factors to the total variance is approximately $54.11 \%$. If the contribution of the explanatory factors to the total variance is higher than 45$50 \%$, these factors can be considered sufficient to explain the test (Bland \& Altman, 1997). The researcher has not carried out Confirmatory Factor Analysis during the scale development process. If the data determined by the scale is stable, if it is sure that the same results will be obtained in the second measurement to be made for the same purpose, and the sub-dimensions in the model are clear without any discussion or doubt, there is no need for CFA.

It has been found out that the split half reliability value of this scale study is 0.93 , the Cronbach Alpha value is 0.94 , the positive behavior factor load is $0.44-0.72$, and the undesirable behavior factor is between $0.62-0.80$. If the factor load value is 0.71 , it has perfect; if it is 0.63 , it has very good; if it is 0.55 or 0,45 it has medium; if it is 0.32 , it has a weak contribution to level of variance. Therefore, it is clear that the results obtained by factor analysis are in parallel with the literature.

This measurement tool, developed by the researchers, will provide data to the educators in order to plan an efficient teaching process at the beginning of their education process. In addition, data can be obtained with the scale to facilitate the selection of the appropriate model for classroom management processes and to make classroom communication healthy. This tool or similar measurement tools can be used both when deciding on the appropriateness of precautionary, reactive or democratic models in classroom management, and to obtain data to be used in modeling teaching. 


\section{Kaynakça / References}

Ada, S. ve Baysal, Z. N. (2020). Sinıf yönetimi (2. Bask1). Ankara: Nobel Yayıncılık.

Akçadağ, T. (2005). Sorun davranışların yönetimi. H. Kıran (Ed.), Sınıfyönetimi içinde (s.277-311). Ankara: Anı Yayıncilik.

Aksoy, N. (2000). Sınıf içi disiplin sorunlarını azaltmada izlenebilecek temel yaklaşımlar. Ë̆itim Araştırma Dergisi, 1(2), 5-9.

Balay, R. (2014). 2000'li yıllarda sınf yönetimi. Ankara: Pegem Yayıncılı.

Balcı, F. A., Çapri, B., Çelikkaleli, Ö. ve Büte, M. (2006). Günümüz toplumunun değişimi ve okullardaki disiplin problemine yansımaları. MEÜ BAP Projesi $R a$ poru (BAP-EF EB (AB) 2005-2).

Başar, H. (2011). Sınıf yönetimi (17.Baskı). Ankara: Anı Yayıncılık

Bland, J. M. ve Altman, D. G. (1997). Statistics notes: Cronbach's alpha. Bmj, 314 (7080), 572.

Büyüköztürk, Ş., Kılıç Çakmak, E., Akgün, Ö. E., Karadeniz, Ş. ve Demirel, F. (2008). Bilimsel araştırma yöntemleri. Ankara: Pegem Akademi.

Celep, C. (2008). Sinıf yönetiminde kuram ve uygulama (4. Bask1). Ankara: PegemA Akademi Yayıncilik.

Charles, C. M. ve Senter, G. W. (2005). Elementary classroom management (4th Ed.). New York: Pearson Education.

Çağlar, Ç. (2008). Sınıf yönetimini etkileyen etmenler. M. Çelikten (Ed.), Yapılandırmacı yaklaşıma göre sımıf yönetimi içinde. Ankara: Anı Yayıncılık.

Çelebi, C. (2019). Views of teachers working at Turkish Schools in England about students' misbehaviors in classroom. Research on Education and Psychology (REP), 3(2), 164-184.

Demir, M. K. (2011). Öğretmen adaylarının karşılaşmak istemedikleri öğrenci davranışlarının analizi. Buca Ĕ̆itim Fakültesi Dergisi, 31, 68-84.

Erdem, H. (2016). İlkokul öğretmenlerinin istenmeyen öğrenci davranışlan ile baş etmede kullandıkları yöntemler. Yüksek Lisans Tezi. Pamukkale Üniversitesi, Denizli.

Johnson, Z, D., Claus, C. J., Goldman Z. W. ve Sollitto, M. (2016). College student misbehaviors: An exploration of instructor perceptions. Communication Education, 66(1), 54-69. doi:10.1080/03634523.2016.1202995.

Kılıçoğlu, C. (2015). Sinff içerisinde istenmeyen davranışlara karşı öğretmenlerin baş edebilme yöntem ve teknikleri. Yüksek lisans tezi, Toros Üniversitesi, Mersin.

Kyriacou, C. (2010). Japanese high school teachers' views on pupil misbehaviour. Pedagogy, Culture \& Society, 18(3), 245-259. doi: 10.1080/14681366.2010.505459.

Okutan, M. (2006). Sinıf yönetiminde örnek olaylar. Ankara: Pegema Yayıncılık. 
Süt, N. (2009). Geçerlilik, güvenirlik ve madde (item) analizleri. M. Ş. Şenocak, (Ed.), Klinik Biyoistatistik içinde (s. 200-205). İstanbul: Nobel Trp Kitabevleri

Tabachnick, B. G. ve Fidel, L. S. (2014). Using multivariate statistics. USA: Pearson Education Limited

Tanhan, F. ve Şentürk, E. (2011). Sınıf içi istenmeyen öğrenci davranışlarına yönelik öğretmen tutumları ölçeğinin geliştirilmesi. Türk Psikolojik Danışma ve Rehberlik Dergisi, 4 (35), 44-53.

Taş, S. (2008). Sinıf yönetimi modelleri. B. Yiğit (Ed.), Sinnf yönetimi teori ve pratik uygulamalar içinde (s. 129-144). İstanbul: Kriter Yayınevi.

Tertemiz, N. (2000). Sinff yönetimi ve disiplin. L. Küçükahmet (Ed.), Simf Yönetimi içinde (s. 49-70). Ankara: Nobel Yayıncillk.

Türnüklü, A. ve Galton, M. (2001). Students' misbehaviours in Turkish and English primary classrooms. Educational Studies, 27(3), 291-305.

Uğurlu, C. T., Doğan, S., Şoförtakımcı, G., Ay, D. ve Zorlu, H. (2014). Öğretmenlerin sinff ortamında karşılaştıkları istenmeyen davranışlar ve bu davranışlarla baş etme stratejileri. Turkish Studies, 9(2), 577-602.

Üstün, Ö. ve Demir, M. K. (2015). Fen ve teknoloji öğretmenlerinin laboratuvar ortamlarında karşılaştıkları istenmeyen öğrenci davranışlarının incelenmesi. Abant İzzet Baysal Üniversitesi Ĕ̆itim Fakültesi Dergisi, 15(1), 281-301.

\section{Kaynakça Bilgisi / Citation Information}

Çelebi, C. ve Arslantaş, S. (2021). Sınıf öğretmeni görüşlerine göre sınıf içi öğrenci davranışlarını belirleme ölçeği geçerlilik ve güvenirlik çalışması. OPUS-Uluslararası Toplum Araştırmaları Dergisi, 17(36), 2586-2604. DOI: 10.26466/opus.827286 